\title{
Digital intelligent microclimate control of livestock farms
}

\author{
Yuri Ivanov ${ }^{1}$, Nikolai Novikov ${ }^{1, *}$ \\ ${ }^{1}$ Institute of Livestock Mechanization - filial of the «Federal scientific agroengineering Center All- \\ Russian Institute of Mechanization», urban village Znamja Oktjabrja, 31, 108823, Moscow, Russia
}

\begin{abstract}
The article presents the livestock structural and hardware implementations, the element base of digital intelligent microclimate control's systems, the tasks must be solved in the light of microclimate quality imposed by livestock production modern technologies' requirements are formulated. It is shown that the microclimate quality by changing of heating (cooling) power and air exchange equipment based on air environment's temperature, humidity, and carbon dioxide content's measurements is provided. An animals' premises microclimate parameters' automatic discrete-analog-digital control has been developed. The livestock farm premises' microclimate system controlling hardware implementation's scheme, including two levels: an electronic computer (farm), controllers with control and measuring devices, an interface, and executive devices (premises) has been developed. The information flows in the control system are determined: tasks are sent from the computer to the controllers for the current values of temperature, humidity, air pollution in the rooms, controllers in communication with measuring devices (radio channel), ventilation, heating (cooling) control devices. An example of the optimal microclimate control system's effectiveness on 1300 heads of pigsty-feedlot is shown.
\end{abstract}

\section{Introduction}

The digital engineering's widespread using opens great opportunities for the livestock premises microclimate control improving [1,2].

According to animals production degree influence, the microclimate is only second to the animals' breed and feeding [3].

The microclimate's state is characterized mainly by its air environment's parameters: temperature, relative humidity, carbon dioxide $\mathrm{CO}_{2}$, as well as air mobility, $\mathrm{NH}_{4}$ ammonia content, $\mathrm{H}_{2} \mathrm{~S}$ hydrogen sulfide, bacterial contamination [4].

Air temperature - is animal body's affecting the most significant factor. A comfortable temperature allows to get high animal production, resistance, feed economy, and other positive effects.

In pigsties in the cold season, the temperature is $+(16 \ldots 23){ }^{\circ} \mathrm{C}[5]$, in cattle premises, it is either no normalized (fattening livestock, some other groups), or $+3^{\circ} \mathrm{C}$ is recommended

\footnotetext{
*Corresponding author novikov-vniimzh@yandexl.ru
} 
and higher [6]. For premises space heating, it gas and electric heaters allowing smooth power control to support are mainly used. It is taken into account that animals themselves are sources of heat [7]. So that, an adult cow allocates $300 \ldots 1050 \mathrm{Wt}$, a pig-350..600 Wt.

During the hot period, the out temperature above $+(25 \ldots 30)^{\circ} \mathrm{C}$ affects negatively on all kinds of animals production [8]. Therefore, due to the climate warming in recent years, livestock premises' air conditioning with the water-evaporative cooling of air using is widespread becoming [9].

Control of the room air temperature that by the power of the heating (cooling) equipment regulating is performed, leading to significant costs. So that, to increase the temperature in a typical pigsty in the cold season in $1{ }^{\circ} \mathrm{C}$, heating power increasing in $3.5 \ldots$ $4 \mathrm{kWt}$ is required.

There in livestock premises also is water and $\mathrm{CO}_{2}$ an intensive evaporating: each adult cattle emits $300 \ldots 500 \mathrm{~g}$ of water vapor and $100 \ldots 150$ liter of $\mathrm{CO}_{2}$ per hour, a pig - is respectively $100 \ldots 350 \mathrm{~g}$ and $35 \ldots 100$ liter. Premises indoor's humidity is usually $70 \ldots 85 \%$, the $\mathrm{CO}_{2}$ gas content it should not be higher than $0,25 \%$ (2500 ppm) [10].

Raw air, especially at low temperatures combined, leads to an animal's diseases and feed consumption increasing. An excess of the $\mathrm{CO}_{2}$ concentration increasing causes an animals blood pressure, a number of respirations, pulse, and at concentration in $6 \%$ or higher, it causes death increasing.

Therefore, the microclimate systems' second regulating parameter, along with the heating (cooling) equipment power, is the air exchange intensity, that the premises' gases and vapors content balancing. Premises ventilation, especially in pig farming, also requires significant energy expending. An air exchange in 1 th. $\mathrm{m} 3$ per hour increasing it may up to $5 \ldots 7.5 \mathrm{kWt}$ of additional power (a pigsty-feedlot for 1300 of heads, in the cold period) to require. Currently, ventilation systems with mechanical and natural motivation, with stepby-step and continuous performance control are widely used.

The microclimate quality and the spend resources amount by the largely level of its automation are determined

\section{Materials and methods}

We will take into account that the main source of influence on the room's air environment parameters are animals: they emit the greatest amount of heat, water vapors and affect the indicators gas content mainly due to $\mathrm{CO}_{2}$ intensive release [11].

$\mathrm{NH}_{4}$ and $\mathrm{H}_{2} \mathrm{~S}$ into the air releasing to the manure cleaning systems' quality is related, and dust - with feeding system is associated. Increased air bacterial pollution during epizootic periods is observed -in special periods of farms operation, when almost all under the personnel supervision under special regulations are performed.

Therefore, we will consider the microclimate control systems based on three parameters of room air, that are subjected to continuous measurement - such as temperature $\left(t_{b},{ }^{\circ} \mathrm{C}\right)$,

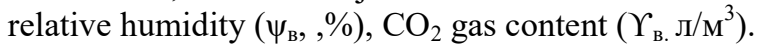

The indoor air's maximum concentration of $\mathrm{NH}_{4}(0,0261 / \mathrm{m} 3), \mathrm{H}_{2} \mathrm{~S}(0,00641 / \mathrm{m} 3)$, dust (4 mg/m3), bacterial contamination $\left(1,78 * 10^{3}\right.$ of microbial colonies per second), air mobility $(5 \mathrm{~m} / \mathrm{s})$, they all as the controlled parameters for corresponding equipment failures' signaling will be considered.

As control actions affecting the microclimate $\left(t_{B}, \psi_{\mathrm{B}}, \Upsilon_{\mathrm{B}}\right)$ parameters are air exchange $(\mathrm{V})$ intensity and heating or cooling $(\mathrm{U})$ units' power are considered.

The microclimate control system must provide the following modes of operation:

- temperature, relative humidity and gas content of the premises room air maintaining at specified intervals near their set values of the weather, season, number of animals, operating equipment's regimes, technical means, etc changing; 
- microclimate's software control (seasonal, at animals growing and moving use, sanitary treatments, etc.);

- optimal control (the best values of microclimate parameters during technological processes' search and maintenance).

Currently, the most widely microclimate systems with automation providing room air's temperature regulation are used, that allows heating energy consumption to reduce. In this case, air exchange by calculation is determined and ventilation equipment operation at nominal modes is implemented [12].

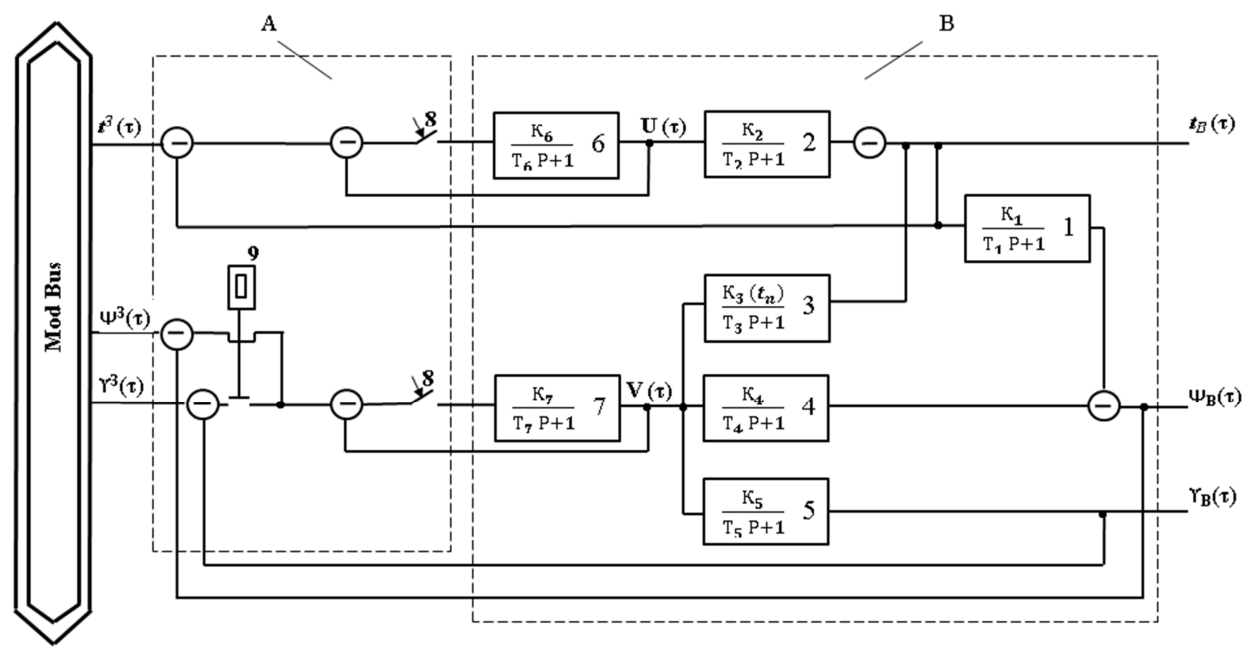

Fig. 1. A structural scheme of estock premises microclimate control. Where: A- controller, Blivestock permises.

Controlling of the room's air exchange together with temperature regulation allow almost in half the energy consumption of these process to reduce, but also the room humidity and $\mathrm{CO}_{2}$ content monitoring is required [13].

The microclimate systems greatest efficiency at optimal parameters' control is achieved. This requires a complex of algorithms for significant amounts of information processing.

A structural scheme of the control system at the premises level in figure 1 is shown. It has the following designations: $\tau$-time, $\mathrm{U}(\tau), \mathrm{V}(\tau)$ current values-heating (cooling) power, air exchange intensity, $t_{b}(\tau), \psi_{\mathrm{B}}(\tau), \Upsilon_{\mathrm{B}}(\tau)$-temperature, relative humidity, $\mathrm{CO}_{2}$ air content, $t^{3}(\tau), \psi^{3}(\tau), \Upsilon^{3}(\tau)$ respectively - their set values from the farm computer are obtained.

Modern means of information-and-measuring and digital engineering allow such systems to create [14].

\section{Results}

The livestock farm premises microclimate control system provides two levels: electronic computer (farm), controllers (premises).

In figure 1, the transfer functions [15] for the heating - temperature, air exchange temperature, temperature - humidity, air exchange - humidity, air exchange - gas content's channels by rectangles $1 \ldots .5$, and the transfer coefficients $\kappa_{\mathrm{i}}$, time constants $T_{i}(i=1 \ldots 5)$ are indicated. 
Rectangles 6 and 7 indicate the parameters of the transfer functions of the heating (cooling) and ventilation capacity control sets (transfer coefficients $\kappa_{\mathrm{i}}$, time constants $T_{i}$ $(i=6,7)$.

The control system works as follows: microclimate current state's data from the measuring devices $t_{B}(\tau), \psi_{\mathrm{B}}(\tau), \Upsilon_{\mathrm{B}}(\tau)$ to the controller are sent and with the $t^{3}(\tau), \psi^{3}(\tau), \Upsilon^{3}$ $(\tau)$ tasks are compared. Based on this comparison's results, the commands to regulatory bodies to change the heating (cooling) equipment $\mathrm{U}$ and air exchange $\mathrm{V}$ modes operating are issued. The controller scheme programmatically gives a control contour's 8 interrupter that by the frequency setting and of its operation adjusting ensures stability, the time for the controlled parameters setting, and a static control error is provided.

Switch 9, is also software-implemented by the controller, it allows to provide the microclimate quality conditions by humidity and room air gas content $\psi_{\mathrm{B}}(\tau) \leq \psi^{3}(\tau), \Upsilon_{\mathrm{B}}(\tau)$ $\leq \Upsilon^{3}(\tau)$, simultaneously, the air exchange control circuit, closing the air exchange control contour that more air exchange in the current time (at the water vapors or carbon dioxide removing condition) providing.

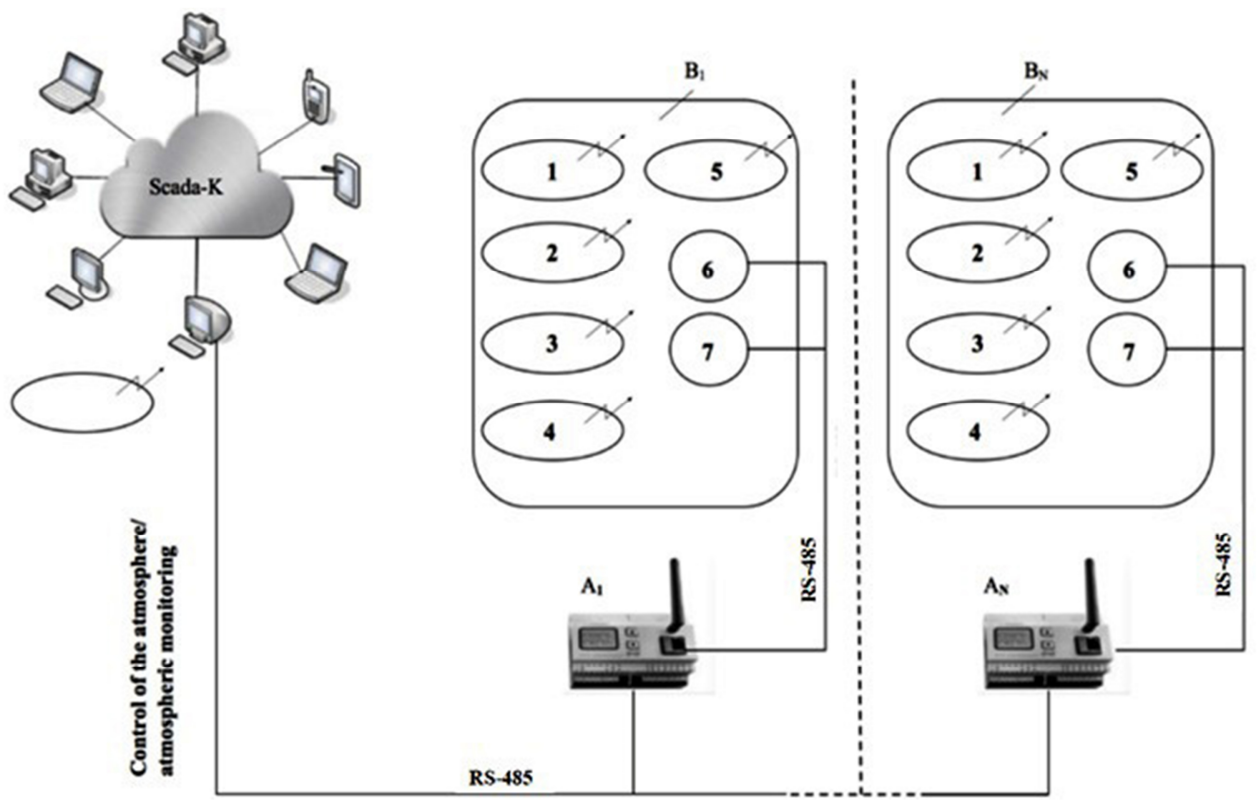

Fig. 2. Hardware implementation of a livestock farm's digital intelligent microclimate control system. Where: 1-4 - temperature meter, relative humidity, air pollution, 5 -air ammonia and hydrogen sulfide content sensor, 6 - heating (cooling) system, 7-ventilation system, $A_{i}$ - indoor climate controller in premises $\mathrm{B}_{i}(i=1 \ldots N)$.

The hardware implementation of a livestock farm's digital intelligent microclimate control system for a is shown in figure 2 .

The system includes a computer with weather conditions' tracking devices, special software (a computer or "the cloud"). It calculates at a specified frequency or on request the values of $t^{3}(\tau), \psi^{3}(\tau), \Upsilon^{3}(\tau)$ task for the farm's premises and passes them to the controllers. The calculation's algorithms are sufficiently developed and assume the microclimate parameters, premises', livestock placement data, etc current standards using. Information in the standard interface system using is exchanged.

The measuring instruments cost's reducing by a set including sensors for the number of measured parameters with one of secondary device using is achieved. It is also very important the number of electrical connection points in the chemically aggressive premises' 
air environment to minimize, that by a radio channel to measuring information transmit at a distance up to $1000 \mathrm{~m}$, sufficient for stable operation within this farm is used.

Figures 3,4 show the appearance and design of devices of EE - series that the above requirements are met [16].

The EE244 Converter allows to measure and transmit over a radio channel $(2,4 \mathrm{GHz})$ at a distance up to $1000 \mathrm{~m}$ : air temperature (operating range from $-40 \ldots+50{ }^{\circ} \mathrm{C}$, error $\pm 0,1^{\circ} \mathrm{C}$ ), relative humidity $(0 \ldots 90 \%, \pm 1 \%), \mathrm{CO}_{2}$ content $(0 \ldots 10000 \mathrm{ppm}, \pm 200 \mathrm{ppm})$. There in the premises, it is enough four EE244 converters evenly along the longitudinal axis to install, the measuring sensors of each converter at a height of $0,3 \mathrm{~m}$ (pigsties) or $0,7 \mathrm{~m}$ (cowbarns) from the floor to place. The averaged data of the measurement results will allow the current actual values of the measured parameters in a room's monoblock and separately in isolated zones' each section to estimate.

a)

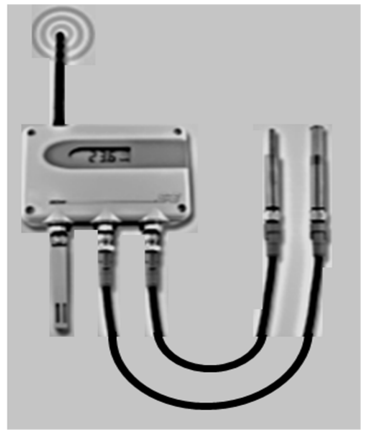

b)

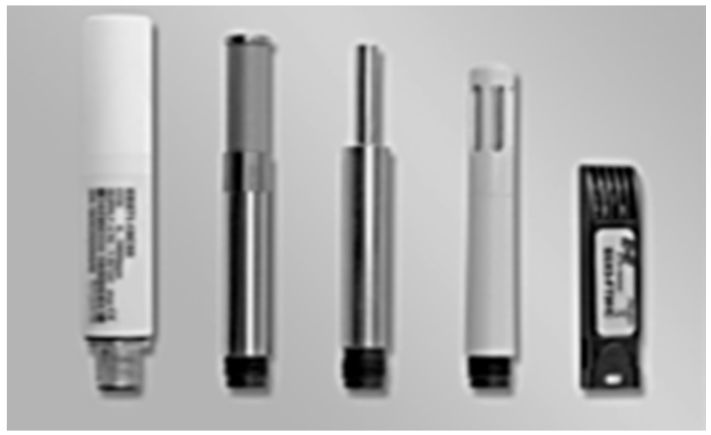

Fig. 3. Measuring converter EE244 (a) with a set of sensors for temperature and relative humidity, air, $\mathrm{CO}_{2}$ content measuring, $\mathrm{NH}_{4}, \mathrm{H}_{2} \mathrm{~S}$ threshold values monitoring (b).

One of such converter with $\mathrm{NH}_{3}$ and $\mathrm{H}_{2} \mathrm{~S}$ sensors indoors are installed and as corresponding gases' concentrations limit sensor's of the manure cleaning system operation monitor to use.

Data collection of EE244 converters by a special base station E242 is performed (figure $4)$.

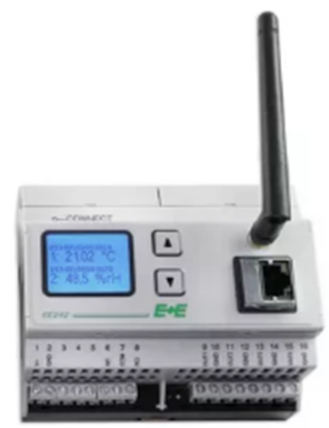

Fig. 4. The base station (controller) E242 for primary measurement information about the room's air environment state from EE244 devices collecting.

The E242 station can up to 500 of EE244 converters serving and has two RS-485 interface connectors, one - for computer's communication, the other - with operating mechanisms. Data correction for the each room's microclimate system parameters control's calculating can from EE244 corresponding controller panel (the number of animals in the room, their average weight, milk yield, etc.) be performed. 
There on the farms usually is the same type of premises where certain groups of animals are kept: feedlots, dams' sheds, cowsheds, etc. Information-and-measuring equipment in complete set for only one of such similar premises are required, for the others control signals according to the control adjusted number of animals, their average weight, rooms' thermal protection's insulation parameters can be generated.

Let's illustrate the microclimate control system operating on feed lot of 1300-head in the optimization regime. In this case, the control system must find and maintain such microclimate regime that, on the one hand, the current standards has met, on the other allows the greatest gain increasing in animals' live weight to get, and as we can see in this case, simultaneously feed costs to reduce.

Data from the graphs in figure 5 [17] for calculations are used. In this example the entire breeding stock's live weight $45 \mathrm{~kg} /$ head is assumed. The animal live weight maximum increasing in the initial period in accordance with the above given charts is $900 \mathrm{~g}$ / day, feed conversion $-3,2 \mathrm{~kg} / \mathrm{kg}$ (fig. $5 \mathrm{~b}$, A). It at a room temperature of $+24{ }^{\circ} \mathrm{C}$ is produced. At animals growing, the maximum position of their mass of growth $(1100 \mathrm{~g}$ /day) shifts towards lower ambient temperatures $\left(+18{ }^{\circ} \mathrm{C}\right)$. Feed conversion till $2.3 \mathrm{~kg} / \mathrm{kg}$ (fig. 5 b, B) is reduced.

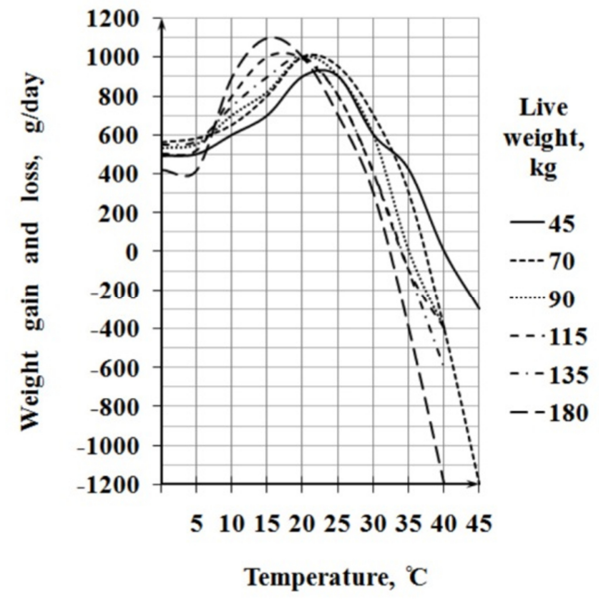

a

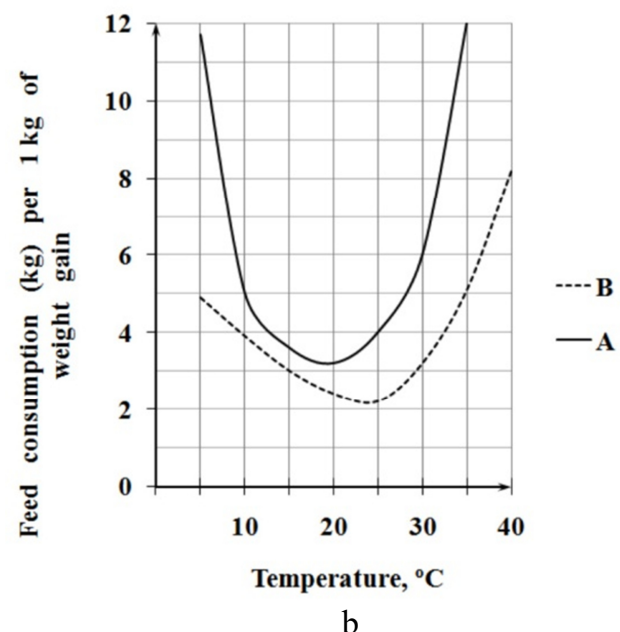

$\mathrm{b}$

Fig. 5. Graphs of fattening pigs' live weight gain (a) and feed conversion (b) in relation to environment temperature.

Figure 6 shows a graph of pig fattening process dynamics at the optimal temperature regime in comparison with $+18{ }^{\circ} \mathrm{C}$ of unchanged ambient temperature. On this drawing vertical axis air temperature current values indoor is $t,{ }^{\circ} \mathrm{C}, 0,1 M_{G}, 0,1 M_{K} \quad\left(M_{G}, M_{K} \quad-\right.$ mass of the animal and accumulated mass of the consumed feed, $\mathrm{kg} /$ head respectively), on the horizontal axis - fattening duration $\tau$, days. 


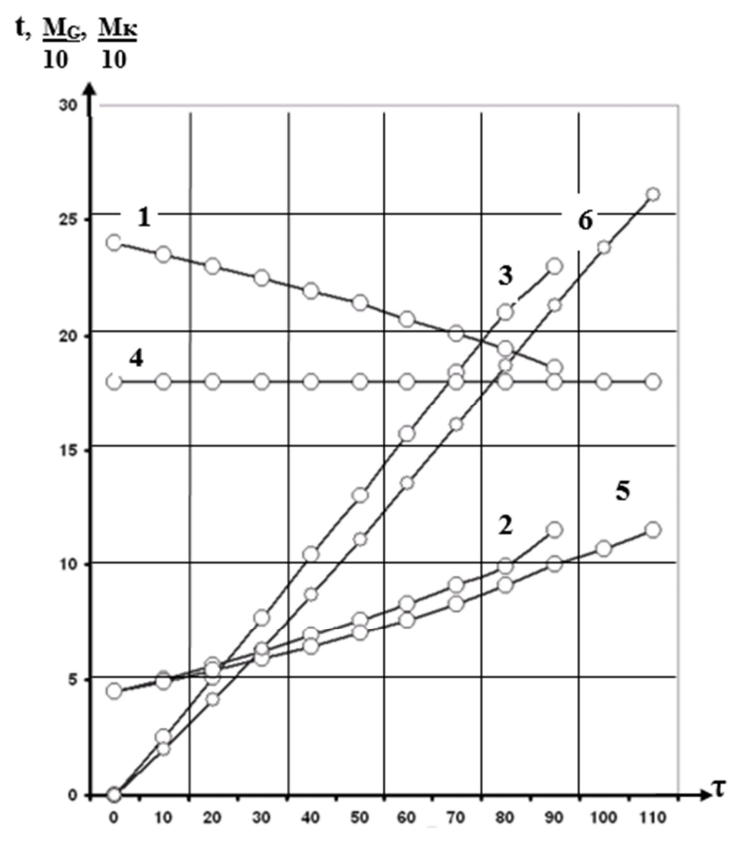

Fig. 6. Graph of 1300 fattening pigs on feedlot' dynamics. Where: 1, 2, 3- air temperature indoor, live weight, feed consumption at the optimal temperature regime respectively; 4, 5, 6- the room temperature, live weight, feed consumption at $\mathrm{a}+18^{\circ} \mathrm{C}$ constant temperature respectively.

At optimum microclimate in pigsty the animals' fattening period till the live weight of $115 \mathrm{~kg} /$ head in from $19 \%$ to 88 days (average daily gain for the period $795 \mathrm{~g}$ ) declining, feed consumption nearly in $10 \%$ in compared to the feeding regime at a temperature of +18 ${ }^{\circ} \mathrm{C}$ reducing. The products output per producing area's unit increasing.

\section{Discussion}

Microclimate systems in livestock premises make it possible better the farm animals' genetic potential to use, high production level to achieve, fertility to increase, morbidity and mortality to reduce, buildings and equipment's service life to increase, farm staff and living population's working conditions in this zone to improve.

The article shows the modern automation importance for microclimate controlling, that allows its positive impact to

Modern technologies of livestock productivity are increasingly saturated with a similar level of automation. These are robots (feed sub-movers, manure cleaners, milkers), feed preparing and distributing's coordinate systems, milking units, etc.

An microclimate's control automation important role is that it creates working conditions for all other livestock automatic devices operating at environments where gases release and vapors is continuous intensive that cause of metal parts of electronic components' corrosion. 


\section{References}

1. A.Yu. Izmailov, Vestnik Rossiyskoy Akademii Nauk. Bulletin of the Russian Academy of Sciences 89(5), 536-538 (2019) DOI: https://doi.org/10.31857/S08695873895536-538

2. M.V. Kovalchuk, O.S. Naraykin, E.B. Yatsishina, Vestnik Rossiyskoy akademii nauk. Bulletin of the Russian Academy of Sciences 89(5), 455-465 (2019) DOI: https://doi.org/10.31857/S0869-5873895455-46514.

3. D. Divyalakshmi, N. Kumaravelu, B. Ronald, S. Masilamoni, Indian Journal of Animal Sciences 87, 93-96 (2017)

4. Hung Soo Joo, P.M. Ndegwa, Xiang Wang, A.J. Heber, Ji-Qin Ni, E.L. Cortus, J.C. Ramirez-Dorronsoro, B.W. Bogan, Transactions of the ASABE, Amer. soc. of agriculture and biol. engineering.-St. Joseph (Mich.) 58(5), 1321-1331 (2015)

5. Yanxi Lu, Morgan Hayes, J.P. Stinn, T. Brown-Brandl, Hongwei Xin, Transactions of the ASABE, Amer. soc. of agriculture and biol. engineering.-St. Joseph (Mich.) 60(1), 237-245 (2017)

6. A. D'Emilio, S.M.C. Porto, G. Cascone, M. Bella, M. Gulino, Journal of Agricultural Engineering 48(4), 190-195 (2017)

7. C. Baxevanou, D. Fidaros, D. Papanastasiou, Environmental Engineering and Management Journal 16, 2513-2523 (2017)

8. S. Hempel, C. Menz, S. Pinto, Earth System Dynamics 4, 859-884 (2019)

9. S.M.C. Porto, A. D'Emilio, G. Cascone, Journal of Agricultural Engineering 48(1), 21 27 (2017)

10. Kaiying Wang, Qiaona Pan, Kaitai Li, Transactions of the ASABE, Amer. soc. of agriculture and biol. engineering.-St. Joseph (Mich.) 60(1), 195-205 (2017)

11. R.W. Melse, P. Hofschreuder, N.W.M. Ogink, Transactions of the ASABE, Amer. soc. of agriculture and biol. engineering.-St. Joseph (Mich.) 55(2), 689-698 (2012) http://elibrary.asabe.org/toc.asp

12. A. Denizopoulou, Z. Andreopoulou, A. Martzopoulou, Journal of Environmental Protection and Ecology 20, 562-570 (2019)

13. Kaiying Wang, Qiaona Pan, Kaitai Li, Transactions of the ASABE, Amer. soc. of agriculture and biol. engineering.-St. Joseph (Mich.) 60(1), 195-205 (2017)

14. P. Jackman, Sh. Ward, L. Brennan, G. Corkery, U. McCarthy, Agricultural Engineering International 17(2), 287-295 (2015)

15. D. Kang, S. Won, Y.J. Jang, Appl. Math. Comput. 219(14), 7398-7405 (2013) https://www.epluse.su/ba/BA_EE240_e.pdf

16. Leistungsfaktor der Tierproduktion (Grundlagen-Technik-Berechnung-NutzungOkonomik-Messmethoden). Von Dozent Dr.sc.agr.Ing. Eckehard Mothes (VEB Deutscher Landwirtschaftsverlag, Berlin, 1973) 